\title{
Letter \\ Accelerated partial breast irradiation: a valid choice
}

Martin E Keisch

Radiation Oncologist, Mount Sinai Comprehensive Cancer Center, Miami Beach, Florida, USA

Corresponding author: Martin E Keisch, mkeisch@salick.com

Published: 24 May 2005

Breast Cancer Research 2005, 7:165 (DOI 10.1186/bcr1269)

This article is online at http://breast-cancer-research.com/content/7/4/165

(c) 2005 BioMed Central Ltd

See related commentary by Ross, http://breast-cancer-research.com/content/7/3/110

In her recent commentary, Doctor Ross [1] puts forth a series of cogent arguments in favor of careful study of partial breast irradiation before its generalized use. The title of the commentary, particularly the phrase 'who will benefit', begs a different perspective than the presentation of existing data for or against the use of any given therapy. Instead, the question asks for a more profound view of the role of any health care provider within any health care system in helping a patient to deal with the medical, social, psychological and financial impact of a disease process.

Just as it is an acceptable option to undergo mastectomy when breast conservation is an option, it is also felt to be acceptable to choose lumpectomy alone if the patient understands the potential for increased local recurrence. In the trial conducted by Fyles and coworkers [2], perhaps more patients would have accepted randomization after lumpectomy if the radiotherapy arm were 1 week instead of 6 . In the USA the patient is given options and, hopefully, the background to understand them. Partial breast irradiation is an option that appears to be roughly equivalent to whole breast irradiation for carefully selected, carefully treated patients. I agree that the ongoing phase III randomized trials in Europe and the USA are important in further refining and developing our knowledge of these newer treatment options. The US study has elaborate quality of life end-points and will shed light on patient's experiences with both whole and partial breast irradiation. Furthermore, by having broad eligibility requirements, the study may help to delineate which patients are ideal condidates for partial breast treatment.

Even after the trials are complete and the data mature, the question will remain because some patients will benefit from different options depending on their particular situation, whether that situation is a medical/pathologic or a psychosocial one. The treating physician will have more information to share with their patients, and will be better able to guide them in making an appropriate choice. Does that mean that partial breast irradiation is an invalid choice now in an appropriately informed patient? l'd say 'no'.

\section{Competing interests}

MEK is a technical consultant to Cytyc Surgical Products.

\section{References}

1. Ross G: Accelerated partial breast irradiation: technically feasible but who will benefit? Breast Cancer Res 2005, 7:110112.

2. Fyles AW, McCready DR, Manchul LA, Trudeau ME, Merante $P$ Pintilie M, Weir LM, Olivotto IA: Tamoxifen with or without breast irradiation in women 50 years of age or older with early breast cancer. N Engl J Med 2004, 351:963-970. 